\title{
Funding for Results in Higher Education
}

by

Alex Usher

- The new Ontario provincial government, in its first budget, announced a radical plan to make 60 percent of its transfers to universities and colleges based on a set of 10 "performance indicators" related to each institution's learner outcomes and economic impacts. This is an enormous shift in public policy, which not only potentially affects more than $\$ 2$ billion of public investments, but one that could set the stage for a wider reconsideration of post-secondary funding across Canada. Therefore, it merits careful scrutiny and needs to be based on the widest possible review of evidence.

- The purpose of this E-Brief is two-fold: first, to review international experiences with Performance Based Funding Systems (PBFs) and, second, to examine Ontario's intention to impose PBFs on the province's 45 post-secondary institutions to see if they are workable and in line with the lessons of international experience.

- Among developed countries, PBF measures for higher education are ubiquitous. What varies is the nature of the performance that is being incentivized, the indicators used to measure them and the size of PBF funding relative to total funding. Broadly speaking, two major areas of institutional performance are rewarded in PBF systems: student progress and completion, and research. In some isolated cases, other outcomes are measured as well.

- The PBF system announced in bare outline by Ontario is consistent with some but not all of the lessons of international experience. The proposal respects the lesson that incentives need to be large in order to affect institutional behaviour and it recognizes that incentives need to be tailored, at least to some extent, to individual institutions. On the other hand, it ignores the lessons with respect to transparency in the development of indicators and in using indicators that are meaningful measures of performance. Most intriguingly, it proposes to look not just at credentials awarded but also at gains in learning/knowledge.

Over the past two decades, one of the biggest trends in public funding of higher education, worldwide, has been to tie a greater percentage of institutional funding to outputs or outcomes in what are called performance-based funding (PBF) systems. In most cases, PBF is an add-on to a

The author thanks Parisa Mahboubi, Janet Ecker, Munir Sheikh, Andrew Thomson, anonymous reviewers and members of the C.D. Howe Institute's Human Capital Policy Council for comments on an earlier draft. The author retains responsibility for any errors and the views expressed. 
public-funding system that is primarily enrolment-based; that is to say, it usually represents only a small portion of government funding and - in countries with tuition fees - an even smaller percentage of total funding. Still, with institutions around the world feeling a constant funding pressure, the logic behind PBF insists that governments can drive significant change by getting higher-education institutions to compete for relatively small amounts of money.

Canada has largely sidestepped this debate. In the late 1990s and early 2000s, Ontario, Alberta and Quebec all dipped their toes into this area with policies that affected almost insignificant (below two percent) proportions of public funding, and the latter two had abandoned this approach by 2017. On the whole, provincial postsecondary funding has remained largely tied to enrolment-based approaches that were developed in the 1960s and 1970s and have changed only marginally since. But in April of this year, the new Ontario provincial government, in its first budget, announced a radical plan to make 60 percent of its transfers to universities and colleges based on a set of 10 "performance indicators" related to each institution's learner outcomes and economic impacts. This is an enormous shift in public policy, which not only potentially affects more than $\$ 2$ billion of public investments, but one that could set the stage for a wider reconsideration of post-secondary funding across Canada. Therefore, it merits careful scrutiny and needs to be based on the widest possible review of evidence.

The purpose of this E-Brief is two-fold: first, to review international experiences with PBFs and, second, to examine Ontario's proposal to impose PBFs on the province's 45 post-secondary institutions to see if they are workable and in line with the lessons of international experience.

\section{Formula Funding Instruments and Their Evolution}

There are a number of ways in which governments direct funds to post-secondary educational institutions. In Canada, until the 1950s, funding was irregular and subject to the whim of the legislature; whatever it felt it could afford to give institutions was more or less what they received. However, as institutions grew more complex and multiplied to become systems of higher education, it became necessary to arrive at structured annual procedures for granting the majority of funds to institutions. While these procedures grew in importance, no government ever surrendered the right to provide money to institutions for specific purposes.

The simplest financing system involves negotiated budgets. In Canada, this was the dominant funding method until the late 1960s, and it remains in operation in countries where government trust in institutions is low. Under this approach, institutions annually develop financial requests for the government, which approves or denies them. Effectively this model gives government a line-by-line veto over institutions' budgets. The government is under no obligation to treat different institutions in a similar manner and favoured institutions often do very well under such systems.

From negotiated budgets, many jurisdictions switched to bistorically based lump-sum funding. In this approach, governments provide each institution with the previous year's allocation (a sum that may have had some relationship to costs, at least at some point in the past) plus or minus a percentage based on the state of public finances and priorities for the year. This is a somewhat fairer system than negotiated budgets in the sense that everyone is treated more equally on a year-to-year basis. On the other hand, to the extent that funding was inequitable in the base year, this system tends to bake in these inequities. This is the dominant method of funding in half of Canadian provinces including Newfoundland and Labrador, BC, Alberta, Manitoba, New Brunswick and PEI. In most of these provinces, this system was adopted in either the 1960s or 1970s, and the initial allocations 
were at least notionally based on student numbers. In contrast, Alberta used an enrolment-based funding system (see below) until 1976 when it switched to a historically based formula, mainly for reasons of simplicity.

Across most of North America today, the dominant funding model is formula funding where the majority of money transferred by governments to institutions is determined by various inputs, such as square metres of space, faculty numbers or student enrolment. Over time, enrolment-weighted formula funding so called because students in more expensive programs are given an extra "weight," allegedly due to higher instructional costs - has become the dominant form of formula-funded systems.

In Canada, Ontario adopted such enrolment-weighted formula funding in the 1970s, Saskatchewan in the 1980s, Nova Scotia in the 1990s and Quebec in 2000. In practice, these systems vary in different ways, such as the percentage of funds distributed on the basis of something other than enrolments, the nature of nonenrolment considerations (e.g., space usage, research intensity) and, especially, the weights accorded to each field of study. Still, all generally provide greater funding for clinical and laboratory-based programs than for mostly classroom-based subjects. Some enrolment-based systems encourage enrolment growth, but this is not a necessary feature as enrolment corridors or caps can be built into the system to restrain growth.

Since the 1980s in most developed countries, there has been a drift - slow and fitful, but a drift nonetheless - toward various forms of institutional funding that prioritize results. Perhaps the most common is some kind of competitive funding. In Canada, this mechanism is rarely used at the provincial level, although the federal government has been using it at the institutional level for large research investments (e.g., the Canada First Research Excellence Funds) and for capital funding (e.g., Strategic Investment Fund) and, of course, for distributing funds to individual researchers through its three research funding councils. In other countries particularly those that provide money for teaching and research in two separate envelopes - this kind of funding approach has been the norm for distributing research funding for many years, through systems such as the UK's Research Assessment Exercise.

In a few countries - Austria is perhaps the most prominent example - results-based funding is at least partially conditional on fulfilling a particular agreed mandate to reach a set of goals. There are echoes of this in the Canadian system: Ontario's existing system of Strategic Mandate Agreements, for instance, sets out goals for institutions, but does not have quite the same direct tie to funding. In some ways, such agreements are a throwback to a negotiated budget system (each institution is negotiating for different amounts of money, based on non-standardized criteria), but with an actual quid pro quo in terms of "return on investment."

Finally, there is PBF, which Ontario has proposed. This type of scheme ties funding directly to institutional results on specific indicators, usually around student performance (especially in the US) and research (especially in Europe). Mostly, these indicators are institutional output measures, (e.g., graduations, publications, etc.), rather than outcomes (e.g., employment rates, average graduate salaries, etc.). They are meant to be simple to implement, relatively easy to understand and, above all, a means to incentivize the institution to behave in particular ways and achieve particular goals.

Briefly, the purported benefits of PBF systems are:

i) they reduce the burden of annual funding negotiations between the state and higher education institutions (HEIs);

ii) they enable the state to enact policy within a framework of HEI autonomy (the government sets goals, but institutions decide how to meet them); 
iii) they contribute to the accountability of the higher-education sector by making the rationale for funding transparent;

iv) they reward performance; and

v) through a combination of transparency and competition, inspire all institutions to improve their outcomes.

Of course, PBFs have some well-known drawbacks, most of which are some variation of Goodhart's Law, namely: "When a measure becomes a target, it ceases to be a good measure." Gaming indicators, particularly when money is attached to them, creates a well-known public policy problem, and PBFs are no exception. Where bibliometric measures have been introduced as funding indicators, scams will sometimes emerge such as increased publications in predatory (or border-line predatory) journals, or citation rings. Furthermore, where completion measures are introduced, an incentive to become more selective in admissions is introduced, etc. To some degree, careful choice and design of indicators can mitigate this risk, as can a robust system of external quality assurance.

\section{Incentivising Outcomes: A Global Review}

Among developed countries, PBF measures for higher education are ubiquitous. What varies is the nature of the performance that is being incentivized, the indicators used to measure them and the size of PBF funding relative to total funding. Broadly speaking, two major areas of institutional performance are rewarded in PBF systems: student progress and completion, and research. In some isolated cases, other outcomes are measured as well. ${ }^{1}$

\section{i) Student Progress and Completion}

By far the most common PBF measurement is with respect to student progress and completion. In the US, 35 states have some kind of performance funding, and all of them are in one way or another concerned with completion. In nearly all cases, these are multi-indicator systems: that is, performance is judged not by one metric but by several. The most common is simply the number of degrees awarded. In many cases, the type of degree is specified (usually a STEM field). Others might be tied to graduation by members of underserved communities (typically African-American and Hispanic students, although "underserved" is sometimes defined with respect to eligibility for specific forms of student aid). Metrics that consider the absolute number of graduates are considerably more common than ones that look at graduation rates (i.e., the number of completions from a given cohort who finish within a given number of years).

One interesting feature of US PBF systems is that they often reward not only completion but progress as well. This is done in response to complaints that completion-focused measures take insufficient account of students' switching among institutions (which is not necessarily a failure), or of the benefits that even partial completion confers. US two-year colleges especially suffer from low graduation rates partly because - by design - students transfer to other, usually more prestigious, four-year schools. A number of states, therefore, reward these

1 Readers wishing a more comprehensive overview of performance-based systems in Europe can consult De Boer et al. (2015), which is perhaps the best multinational review of this subject. For a more up-to-date review of PBF systems with specific regard to funding for student progression and completion, see Orr and Usher (2017). 
colleges for students who obtain their first 30 credits (equivalent to one year of full-time studies) and a smaller number of states do the same for students from under-represented backgrounds (again, mainly black and/or Hispanic) to finish a certain number of credits. In North Dakota and Wyoming, credits completed are the only metric used in the performance-based formula.

In Europe, the most famous example of a student-completion PBF is Denmark's "taximeter" system, introduced in 1994. In Denmark, 90 percent of university budgets come from the state, with roughly two-thirds devoted to research and one-third to teaching. One hundred percent of the teaching component is based on the taximeter system, which at the outset was based simply on the number of courses that students passed (the value per course is weighted according to program costs, as in most enrolment-weighted systems). Later, the system was modified so that HEIs also received a bonus for high rates of timely degree completions. In late 2017, however, in response to concerns that the system emphasized quantity over quality, the system reverted to being mostly enrolment-weighted ( 67.5 percent), with just 7.5 percent based on completion rates. The balance (25 percent) is paid through a "basic grant," part of which is tied to quality assessments that include information gained from student satisfaction questionnaires.

England is not often reckoned to have a PBF system because the funding distributed by the Higher Education Funding Council for England superficially looks like it is subject to an enrolment-weighted funding formula, with a multi-band system for funding programs of different costs. However, the only students funded by this system are ones who finish their year of studies, so technically it is enrolment-weighted conditional on completion. In practice, this works the same way as the Danish taximeter system. Since 2012, the UK government no longer subsidizes undergraduate study in humanities, business, social sciences, geography, mathematics, languages or psychology. As a result, completions in these areas have no effect on government funding. Instead, the subsidies are directed to the pure sciences, engineering, health sciences, etc.

For its part, Finland has a complex multi-indicator PBF system that governs 75 percent of its funding formula. At the university level, one-third of public funding is based on degree completion at various levels, and another 8 percent based on students achieving a year's worth of credits. At the polytechnic level, half of the PBF funds are dispensed based on completion and a quarter on first-year credits.

Meanwhile, Norway in 2002 adopted a funding system in which 25 percent of institutional funding was based on the numbers of credits, graduates and educational exchange students. (The measure relating to credits is the number of students obtaining 60 credits, a yardstick very similar to the one adopted in neighbouring Finland.) And Italy in 2004 introduced similar measures with respect to degrees and credits, as did Flemish Belgium in 2008.

In the Netherlands, roughly one-third of university base funding (or one-fifth of total funding) is tied to degree completion. Similarly, Slovenia and Latvia also use degree completion in their PBF formulas. In Germany, where each Land, or province/state, has its own funding system, all use PBF to some degree, although its importance ranges from under 2 percent of total funding in Saxony and Bavaria to 25 percent or more in Hesse and Berlin. The specific indicators also vary, but in general there are three student completion indicators: graduates at the bachelor's and master's levels, doctorates (a measure of research rather than teaching performance, but a completion-based measure nonetheless) and "percentage of current students who are within their study period." The latter is not technically a credit or a completion measure, but rather a slightly roundabout way of rewarding quicker times-to-completion.

France has perhaps the most complicated system of funding student completions. Five percent of total public funding is based on measures of "teaching performance," which use various types of progress/completion metrics. Perhaps the most complicated is a "value-added" calculation for "réussite licence" (i.e., Bachelor's 
success), which is a mix of first-to-second year progression rates and degree-completion rates, adjusted to take account of the nature and quality of institutional student intake as measured by average secondary school results. This measure thus rewards those institutions that achieve the best results with students of more modest academic backgrounds.

Some of the more interesting PBF applications are found south of the equator. In 2010, New Zealand adopted a PBF system worth up to 5 percent of total institutional funding. There are four measures of progress and completion, and they apply to all higher-education providers although they are weighted differently for different qualification levels. What is interesting here is the way this summative data, collected for performance funding, is also used for formative assessments for quality assurance purposes. Institutions are required to keep such statistics not only at the institutional level but also separately for Maori and Pasifika students, who tend to have lower completion rates. Institutions must monitor these rates and produce institutional plans to continually improve them.

\section{ii) Research}

In North America, PBF for research is essentially unknown up to now, except in the limited sense that "overhead" or "indirect cost of research" funding follows grant funding from public agencies such as Canada's Natural Sciences and Engineering Research Council or the US National Science Foundation. In Canada, research funding is instead provided in two ways: "base" funding that compensates professors for their time, which is tied to a combination of tuition fees and general government allocations, while direct funding comes through competitive grant processes.

Elsewhere in the world, though, PBF for research is a live issue. In many countries, governments split operating funds between teaching and research pots, with different allocation rules for each. For research funding, performance is almost always a criterion. Sometimes, the performance criteria allocate funding simply along lines that mirror the competitive grants of national public research agencies. However, funding also follows a number of other indicators as well. In Australia, Austria, Finland, Germany, New Zealand and Norway, public funding follows research income from private sources as well as public ones.

Meanwhile, bibliometric indicators play a funding role in Belgium, the Czech Republic, Denmark, Finland, Norway, and certain German Länder. The Czechs, Norwegians and the State of Berlin also make allowances for works of artistic creation for schools of art and music. Patents and spin-offs are inputs to PBF systems in Belgium and Poland. The number of doctoral degrees awarded contributes significantly to institutional income in Australia, Germany, the Netherlands, New Zealand and Norway. For their part, Finland and Poland attach money to projects that involve international collaboration. Finally, New Zealand and the UK, which both deliver research money via institutional and departmental review processes (rather than on the basis of indicators directly), both include measures of peer esteem in their funding analyses.

\section{iii) Other measures.}

Although the bulk of PBF is for student completion and academic research, a few other outcomes/outputs are also used. For example:

- In the US, seven states use graduate employment measures as an indicator of institutional performance. Finland also provides 1 percent of its PBF money for positive graduate employment outcomes; the Czech Republic also rewards institutions based on low unemployment rates. 


\section{Box 1: European vs. US Approaches to PBF}

There are some significant differences in the US and European PBF regimes. In Europe, government funding almost always makes up a larger percentage of institutional funding, even though US PBFs sometimes have many more indicators. In other words, indicators tend to be more meaningful in Europe.

There are two reasons for this. First, US university budgets are, for the most part, no longer financed through public appropriations. Tuition and other types of income make up the majority of the budgets, even in state schools. In stark contrast, government funding can make up 90 percent or more of institutional budgets in many European countries. Clearly, a US PBF system that makes up 10 percent of the government funding envelope uses far fewer public funds than one worth a similar percentage in Europe. Indeed, the gap is even larger, because the percentage of funding that is at risk because of PBF regimes is usually substantially larger in Europe than in the US. Indeed, US PBF systems rarely account for even 10 percent of state funding (and hence just 2 percent or 3 percent of total funding), whereas in Europe, figures of 20 percent or more are common.

This speaks in part to a slightly different perception of PBFs. In the US, they are seen as accountability mechanisms, or ways of focussing institutional attention on specific issues. This view also exists in Europe, but to a significant extent PBFs there also act as a kind of quasi-market mechanism in the absence of tuition. In the US, elite universities collect more money because they charge higher prices; in Europe PBFs try to mimic that dynamic in the absence of actual tuition fees by providing higher allocations to "elite"performing institutions.

Another difference between the two continents is that the US applies many more indicators in its PBF systems. The power of any single indicator to drive institutional funding is thus much less in the US, even before one considers the difference in the amount of funds involved.

- Four US states use success rates on various professional licensure exams (bar exams, medical licensing exams, etc.) as a PBF measure.

- A number of European countries, including Finland, the Czech Republic and Austria, have some measure of internationalization in their funding formula. Most often, these measures are based on simple counts of undergraduate or master's students enrolled at the institutions - the Czech Republic also attached funding to the number of outbound students and to a measure of international collaborations undertaken by institutions.

- The newly announced (post-2017) Danish system includes a small portion of its funding to be determined by surveys of student satisfaction.

- Equity goals can also be funded through PBFs. Austria, for instance, attaches a small amount of funding to increasing enrolment of female doctoral students and hiring female professors.

As should be evident from the brief tour d'horizon above, there is no shortage of examples of PBF systems that Canadian provinces could learn from if they so choose. Indeed, there are even some limited examples that one could point to within Canada itself. Three Canadian provinces have dabbled in performance-based systems, 
albeit in very small doses. For some years in the 1990s and 2000s, Quebec's enrolment-weighted system was complemented by a very small bonus for completions. Similarly, Ontario for more than two decades provided a little more than 1 percent of total post-secondary funding on the basis of completion rates. Starting in 1994, Alberta provided 2 percent of its funding based on a basket of nine indicators, mostly related to student outcomes and research, although this funding envelope was abandoned a decade ago. Alberta and Quebec abandoned these key performance indicators in large part because they were too small to have any noticeable effect on institutional behaviour.

\section{Is PBF Effective?}

A key question, of course, is whether PBF actually achieves a government's objectives. This is a difficult question to answer because the research methods often used to examine outcomes fall far short of providing conclusive evidence.

In social sciences, when one wants to evaluate effectiveness, one usually tries to examine a "treatment" and compare results to some kind of non-treatment counterfactual. In the US, when examining state-level policies, analysis relies on difference-in-difference regression analyses that either compare one state that has introduced a new policy to the other 49 states, or separate the 50 states into those with and without PBF systems. ${ }^{2}$ The problem is that it is not at all clear that the various PBF systems are similar enough to be considered a single type of "treatment." It is not simply that these programs incentivize slightly different things in slightly different ways using (in some cases) very different amounts of money; even attempts to standardize analyses by looking at the number of indicators or the size of the performance envelope are futile. A PBF with a small value based on indicators that can fluctuate significantly might be a more disruptive force than a PBF with a large value based on indicators whose values move glacially.

Complicating matters still further is that state PBF systems are often designed in such a way that at the point of introduction they alter the distribution of funds across institutions as little as possible, and instead allow the effects to accumulate over time. This makes eminent sense if one is committed to institutional stability, but it makes a difference-in-differences evaluation approach basically impossible because this comparison is about finding discontinuities while the prevailing practice in PBF design is to avoid them.

Therefore, it is not surprising that none of the statistically based analyses of US PBF schemes that incentivize student completion have demonstrated that their introduction has had much of an effect. Whether this is due to the fact that most of the programs being compared are of relatively small weight - perhaps putting as little as 1 percent of total funding at risk - or whether if, as noted above, this is a fundamentally wrong-headed approach is unknown. More narratively driven PBF studies, ones that focus on data-gathering and interviews at the institutional level, find a somewhat different result: that, in fact, institutions do change policies quite substantially to improve graduation rates, at least in cases where very large incentives are on offer. ${ }^{3}$ Perhaps surprisingly, there do not appear to have been any studies on the effectiveness of student-performance-based systems in Europe (the Danish taximeter system has been the subject of a number of reviews, but they all pertained to the impact on institutional finance and functioning, not on student outcomes).

2 See, for example, Tandberg and Hillman (2014) and Hillman, Tandberg and Fryar (2015).

3 See, for example, chapters 4 and 5 of Doughtey et al. (2016) and also Ness, Deupree and Gándara (2016). 
With respect to research-focussed PBFs, an OECD review (Box 2010) suggested that countries that introduced such systems - and recall that these systems tend to have fairly large amounts of funding - saw significant improvements in research outcomes, but that evidence linking this in a causal fashion was scarce. (Some might argue that universities are not in much need of additional incentives to pursue research, since a bias toward research activity is baked into the prevailing academic mindset). The OECD review also noted that there might have been some unintended consequences to the introduction of research-based PBFs, including a narrowing of research focus at certain educational institutions, although evidence for such causal linkages is limited.

In short, the US evidence seems to show conclusively that PBF systems in which only small amounts of funding are at risk have not affected outcomes greatly although institutions have, indeed, changed policies as a result. However, there is reason to suspect some of the methods used to measure outcomes might be inadequate to the task of measuring these policies' real effects. The European perspective, on the other hand, is that their systems that reward outcomes (mainly research) in a much more substantial way have, indeed, succeeded in changing outcomes.

Thus, there is some reason to believe that the incentive size plays a role in PBF effectiveness. One possible explanation for this lies in the nature of universities themselves. They are, famously, loosely coupled institutions - their component parts work largely autonomously and central control is limited. To a significant extent, post-secondary administrations have only limited control over the day-to-day workings of individual faculties or departments, which is where most of the decisions that impact institutional output are made. When confronted with US results on the limited effectiveness of PBFs, one may well ask: is it because the incentives are too small to attract policy attention from the central administration, or because the available mechanisms are insufficient to impact outcomes?

Clearly, the first of these issues is size-dependent: there must be enough money at risk for institutional heads to heed a particular policy outcome. This is, crucially, not simply an issue of the budget percentage tied to a specific indicator or set of indicators, but rather the expected return from the introduction of a new system. For example, one could create a 100 percent outcome-based PBF, but if the distribution of dollars across institutions did not change, one might not expect institutions to react very quickly (or at all) to its introduction.

But the second question - whether a central administration actually can affect outcomes - is more nuanced and depends considerably on institutional mission, culture and the nature of the policy goal being incentivized. If the desired policy outcome is in line with institutional values - better research outcomes, for instance - then all the institution's loosely coupled parts may cooperate toward achieving that goal, especially at a research-intensive institution. But if what is being incentivized is somewhat contrary to culture - a more open access policy at a selective institution, or a more applied-science orientation at an institution that historically values basic science then a larger incentive may be required.

From the foregoing evidence, there are perhaps three major lessons that can be learned from the PBF literature.

1. Go Big. We have little conclusive evidence that any PBF system works to improve outcomes as intended. What we do know for certain, however, is that the US approach - which tends to involve small amounts of money - does not deliver measurable results. This aligns with what we would expect of the behaviour of loosely coupled institutions such as universities. The reward needs to be large enough for all parts of the institution whose participation is required to pay attention. A system with 10 indicators that collectively affect an envelope worth 3 percent of total government funding in a system where government funding accounts for only half of institutional income $\left(.1^{*} .03^{*} .5=\right.$ each indicator accounts for $1 / 15^{\text {th }}$ 
of one percentage point of total income) is almost certainly not going to achieve the necessary internal alignment to affect those indicators.

2. Institutional Culture Matters in Designing Incentives. The purpose of $\mathrm{PBF}$ is to incentivize certain types of activity. But many outcomes currently prioritized in PBF systems are, by and large, already incentivized within higher education's value system. In North America, at least, it is probably not necessary to reward institutions for results like publications and citations, because the tenure and promotion system is already designed to deliver this outcome. PBF mechanisms should, therefore, probably be reserved for outcomes that are not currently incentivized (such as widening participation to underserved groups, for instance).

3. Good PBFs Require Meaningful Indicators, High-quality Data and Transparency. The most legitimate concerns about PBF is that indicators must be valid, reliable and as little subject to gaming as possible. This requires some considerable thought in their crafting and considerable investment in highquality, auditable data collection. As a matter of good practice, both the development of indicators and the handling of annual data collection should be as transparent and as open to public scrutiny as possible.

With these lessons in mind, we can now turn to evaluate the new Ontario model.

\section{The Ontario Plan}

In its April 2019 budget announcement, the province said it would introduce a performance-based element to the basic funding formula for both colleges and universities that would eventually grow to cover 60 percent of provincial funding. Given the size of provincial funding relative to total funding, this implies that the new PBF would be worth roughly one-quarter of total institutional funding (i.e., including all fees and self-generated funding). In simple dollar terms, this would make Ontario the largest PBF system in North America, although as noted previously, the size of the envelope does not necessarily equal the amount of money at risk in practice.

The government has not, in the five months since making this announcement, published its PBF details, although there have been consultations with the executive teams at the province's universities and colleges and some details have leaked via this process. ${ }^{4}$ Apart from the audacious size of the proposed PBF system, there are three other elements of particular interest. First is the general nature of the 10 proposed indicators that would comprise the PBF system: unlike most US PBF systems, only one of the 10 Ontario indicators has to do with student completion. Both in its size and its breadth of indicators, the plan is more European than US in appearance. Second, several of the indicators are genuinely innovative in the sense of never having been tried anywhere. In some cases, this is welcome; in others, it appears as if the government has simply not done its homework. Third, and perhaps most importantly, the actual allocation mechanism that would distribute the money appears to have never been used elsewhere.

Six of the 10 proposed indicators have to do with what are called "student outcomes." These include:

- Graduation Rates, which will likely be further defined. Currently at Ontario institutions this rate is defined as the "percentage of first-time, full-time undergraduate university students who commenced their study in a given fall term and graduated from the same institution within six years." This definition does not address the issues around continuation elsewhere and the benefits of partial completion that have been a focus of much recent discussion in the US.

4 See Friesen (2019). 
- Graduate Employment, which will be defined as the "proportion of graduates employed full-time in fields closely or partly related to one's field of study." This question is currently asked on both the university and college versions of Ontario Graduate Surveys, but results are not currently published at an institutional level. Because this is a self-reported question, the government will not have to provide its own definition of what "related" or "partly related" means.

- Graduate Earnings. The government wishes to measure graduate earnings but has not said over what period of time (at present, the Ontario standard is either six months or two years after graduation). It appears to want to use Statistics Canada's new Educational and Labour Market Longitudinal Platform in which graduate incomes can be tracked through the tax system.

- Experiential Learning. The government says it wants to measure the "number and proportion" of graduates from programs (in the case of college) and courses (in the case of universities) with experiential learning components. The reason for the different language in the two sectors is not known.

- Institutional Strength/Focus. The government wishes to measure the "proportion of students in an area of strength" at each institution, with "area of strength" left undefined.

- "Skills and competencies." The government has given no direction about what it meant when it said it wanted graduate "skills and competencies" to be an indicator, but it is widely assumed that this is related to work the Higher Education Quality Council of Ontario has been doing administering tests to graduating students based on the OECD's Programme for the International Assessment of Adult Competencies.

There are then another four indicators that are meant to be related to "economic impact," broadly defined. These are:

- Research Funding and Capacity, defined by how much federal tricouncil research funding each institution receives (for colleges, a proposed replacement metric relates to apprenticeships, but is undefined);

- Innovation, defined as industry funding (for universities, this is specified as "research income" from industry; it is unclear if this excludes funding from private charities, which are a significant source of income for the medical sector);

- Community/Local Impact, defined as institutional enrolment divided by community population; and

- An Institutionally Defined Metric Related to Economic Development, which each institution can tailor to its own mission and priorities.

Clearly, this revolutionary scheme is about far more than student academic completion: it covers a number of outcomes that are of legitimate public policy interest. In this sense, the plan is substantially more ambitious than any other North American PBF system (and most European ones, too). From a simple measurement perspective, only about half the indicators appear to be well defined. Of the nine indicators which are meant to be centrally defined, five - graduation rates, graduate employment, graduate earnings, earnings from industry and tri-council funding for universities - are reasonably easy to define. While the experiential-learning indicator is not precisely defined, it is clear what the government is trying to reward. These data are all collected right now one way or another and using them for PBF purposes can be done with little effort and at very little cost. For the remaining indicators, the definitions are much less clear or obvious and therefore may pose measurement challenges.

Quite apart from any difficulties in measurement, there are legitimate questions to be asked about the rationale behind some of these measures. It could be argued that both the completion and research measures 
are already incentivized under the present system through tuition/enrolment subsidies in one case and grants and prestige in the other. In contrast, the indicator for "institutional strength/focus" seems very easy to game, since all any institution need do to perform well is to name its largest faculty as its area of strength. And the indicator for "community/local impact" is not a performance measure by any possible definition; rather, it is simply a reward for being located in a small community. As well, bizarre measurement difficulties seem certain to ensue for institutions with campuses in multiple communities.

But while several of these ill-defined indicators might justifiably invite derision, one of them - regarding skills and competencies - is also potentially the most intriguing and game-changing of them all. As a basis of funding, it is new territory, although these types of attributes have been measured in many countries through the OECD's Programme for International Assessment of Adult Competencies (PIAAC), and its Assessment of Higher Education Learning Outcomes (AHELO). ${ }^{5}$ Still, no one has yet linked institutional funding to these kinds of measures. This is in part because there is not a great deal of public literature available on the extent to which HEIs make a difference to these outcomes.

In theory, it is possible to measure such outcomes institutionally: for example, by devising a test that measures literacy, numeracy and problem solving, and giving it to both first- and final-year students. The difference can be counted as value-added by the institution, and this result can be used to compare institutional performance. Such learning outcomes have been measured at hundreds of US institutions over the last 20 years using the US College Learning Assessment (CLA) tool and at hundreds more around the world - including a number of Ontario universities - during the OECD's AHELO pilot project. However, none of these results are public: US institutions use their CLA results to benchmark performance internally but do not make results public, and institutional pressure led the OECD AHELO results to be effectively suppressed. In Ontario, the Higher Education Quality Council has continued experimenting with measurement of graduate skills through its Essential Adult Skills Initiative $^{6}$ and Postsecondary and Workplace Skills ${ }^{7}$ projects, and while it has published results, it has not done so on an institutional basis.

So, even if one believes that these kinds of tests are meaningful measures of transversal skills (and this point is not universally accepted), there is not a great deal of data to suggest whether they are able to measure meaningful differences in skill growth once differences in factors like fields of study are controlled for. Given the inevitably high cost of such a measure - testing every student in Ontario twice in their post-secondary career is not cheap, and samples are unlikely to be acceptable because of concerns about bias - the lack of clear data guaranteeing that it will produce usable results is a major concern. Still, the idea of measuring institutional outcomes by skills learned rather than credentials awarded is appealing in theory.

The final area of potential controversy in Ontario's approach has to do with the mechanism for disbursing funds. There are two general ways this could be done. For very simple systems, which measure only one thing (for instance, completions), funding can take the form of a bounty: e.g., $\$ 1,000$ for every graduate, $\$ 2,000$ for every graduate from an underserved minority, etc. A more common approach is envelope funding - that is, where the government budgets a certain amount of money for the performance-based fund, and each institution gets a share of these funds based on its performance. Essentially, each institution is given a total number of

5 See OECD (2013).

6 See Weingarten (2018).

7 See Finnie et al. (2018). 
performance "points," and its PBF envelope share is equal to its points share among all institutions competing for that envelope. For this to work, each indicator needs to be scaled (for instance, one graduate = one point; $\$ 10,000$ in research funding $=$ one point, etc.), then these scaled indicators need to be weighted (as in rankings, with weights summing to one) and then the weighted scaled results need to be added together to arrive at a points total.

Given Ontario's intention to make 60 percent of the post-secondary funding system performance-driven, the easiest way to do this would be to gradually transfer three-fifths of the current enrolment-driven envelope into a new PBF envelope and allow institutions to compete for that money. However, this does not appear to be the preferred option. Again, although the government has released no white paper or anything else on the subject, it has briefed stakeholders that it does not want institutions to "compete against each other" but rather "compete against themselves" with each institution potentially having different targets and different weights for the 10 indicators. What this seems to mean is something like a marriage between a PBF system and an agreed mandate system: that is, each institution would be given a target to reach for each indicator - in effect, a contract for performance - and the extent to which an institution fulfilled this indicator would determine its funding.

Such a system may attract those who instinctively worry that competition inevitably favours some institutions over others, although the current enrolment-weighted system has implicit competition. But PBF creates a new set of problems that do not exist under the envelope system. It implies that every institution has not just a set of targets but an actual maximum budget as well (that is, the amount of funds it would receive if it meets all its targets). But it is unclear how this maximum budget to be set. Indeed, how will individual indicator targets be set? If they are by negotiation, institutions will have an incentive to try to set the bar low, and thus make it easier to meet them and receive more money.

There is also the question of what happens when institutions surpass or fall below expectations. For instance, an institution might theoretically fail so disastrously to meet its targets as to lose its entire PBF stake, equal to 60 percent of its current formula funding. Today, if an institution performs poorly, money automatically flows to other institutions. This would be difficult to arrange under the PBF contract system, and it seems likelier that

any lost money would go back to the treasury. Therefore, one might suspect that the PBF contract system may, in practice, be a disguised funding cut.

\section{Conclusion}

PBF is neither a flash in the pan, nor some kind of radical ideological tool. It is a mainstream policy instrument in use in places as disparate as Finland and Tennessee, France and Georgia, Norway and Ohio. There is a great deal of variation in detail - notably what is being incentivized and the size of the incentive. Although a lack of counterfactual evidence makes it difficult to make clear-cut statements about the superiority of PBF over other funding systems, it seems relatively clear that government goal-setting can help institutions focus on specific issues. That said, the complex nature of post-secondary institutions - particularly universities - may make them less susceptible to steering through such incentivized financial systems. This is not an argument against PBFs, but it is an argument against placing elevated hopes in them, and in favour of paying attention to institutional culture when developing them.

The PBF system announced in bare outline by Ontario is consistent with some but not all of the lessons of international experience. The proposal respects the lesson that incentives need to be large in order to affect institutional behaviour and it recognizes that incentives need to be tailored, at least to some extent, to individual institutions. On the other hand, it ignores the lessons with respect to transparency in the development of 
indicators and in using indicators that are meaningful measures of performance (the "community impact" indicator is a particularly flagrant offense). Most intriguingly, it proposes to look not just at credentials awarded but also at gains in learning/knowledge.

These features qualify the government's proposal as a whole as ambitious and even audacious, even if the skills piece, perhaps, needs a little more testing and work to be considered ready for implementation.

That said, there are several very real questions that surround the as-yet sketchy descriptions of the proposed implementation. First, the preference for a contract-based PBF rather than an envelope-based system raises serious concerns that this is less a performance measure than a stealth cut to institutional grants. The province needs to clarify this point very quickly - the project's legitimacy depends on it encouraging performance rather than disguising austerity. Moving to an envelope-based system where the entire envelope gets spent on post-secondary education, one way or the other, which is the global standard, would be the most efficient way to ensure that money budgeted for post-secondary institutions actually ends up benefitting post-secondary institutions.

Second, some of the indicators - particularly the one for "community impact" - are badly constructed and may function as the very opposite of a performance measure. Inclusion of such measures weakens the perception that the scheme is in fact meant to encourage performance.

Third, none of the chosen performance indicators reward efforts to expand access. In fact, given the incentive to achieve high completion rates, one might even suggest that there is a bias in this system against widening access to underserved groups, since such an indicator disincentivizes recruiting anyone perceived as a dropout risk. Even if one rejects a moral imperative to keep encouraging institutions to widen access, a pro-access indicator is important to stop institutions from gaming the completion indicator by reducing access.

Perhaps the most worrying aspect of the current plan is the secrecy surrounding it. The public announcement made in the budget contained few details, and the only subsequent information that has come forward has emerged from private government briefings to institutions - public follow-up has been non-existent. Public policy suffers when it is developed in the dark; greater transparency and public participation in the development of a policy governing more than $\$ 2$ billion in public funds is a must.

That said, the principles underlying PBF systems are good ones. It is fully right and proper for governments who still fund a large proportion of higher education costs - to set some goals for post-secondary institutions, while permitting autonomous institutions to decide how to meet these goals. In this sense, the Ontario scheme, sketchy and occasionally poorly thought through as it is, deserves commendation. The challenge now is for the government to change these very rough ideas into a workable policy that, through careful measurement of matters that are actually under institutional control, truly rewards those institutions that are meeting public needs. If it succeeds in doing so, the idea could spread and revolutionize higher education funding throughout Canada. 


\section{References}

Box, Sarah. 2010. “PBF for Public Research in Tertiary Education Institutions: Country Experiences.” In OECD PBF for Public Research in Tertiary Education Institutions: Workshop Proceedings. Downloaded Aug. 23, 2019 at https://doi.org/10.1787/9789264094611-en.

De Boer, Harry, et al. 2015. PBF and performance agreements in fourteen higher education systems. University of Twente. Centre for Higher Educational Policy Studies.

Doughtey, K.J., et al. 2016. Performance Funding for Higher Education. Baltimore: Johns Hopkins Press.

Finnie, Ross, et al. 2018. Measuring Critical Thinking Skills of Post-Secondary Students. Toronto: Higher Education Quality Council of Ontario.

Friesen, Joe. 2019. "New Metrics for Ontario university and college funding include employment and graduation rates." Globe and Mail. April 16.

Hillman, Nicholas, David Tandberg, and Alisa Fryar. 2015. "Evaluating the impacts of 'New' Performance Funding in Higher Education." Educational Evaluation and Policy Analysis 37(4): 501-519. December.

Ness, Erik, Mary Deupree, and Denisa Gándara. 2016. Campus Responses to Outcomes-Based Funding in Tennessee: Robust, Aligned and Contested. Tennessee Higher Education Commission. Downloaded Aug. 23, 2019 at https://www.tn.gov/content/dam/tn/thec/bureau/fiscal_admin/fiscal_pol/obff/research/ Campus_Responses_to_OBF_in_Tennessee_-_Ford_Foundation.pdf.

OECD. 2013. Assessment of Higher Education Learning Outcomes, 3 vols. Paris.

All volumes available at: https://www.oecd.org/education/skills-beyond-school/ testingstudentanduniversityperformancegloballyoecdsahelo.htm.

Orr, Dominic, and Alex Usher. 2017. "Revisiting student performance as a cornerstone of higher education - how is student performance reflected in PBF?" in Hazelkorn Ellen, Hamish Coates, and Alexander McCormak (eds). Research Handbook on Quality, Performance and Accountability in Higher Education. Edward Elgar Publishing.

Tandberg, David, and Nicholas Hillman. 2014. "State Higher Education Performance Funding: Data, Outcomes, and Policy Implications.” Journal of Education Finance 39 (3): 222. Winter.

Weingarten, Harvey, et a1. 2018. Measuring Essential Skills of Post-Secondary Students: Final Report of the Essential Adult Skills Initiative. Toronto: Higher Education Quality Council of Ontario.

This E-Brief is a publication of the C.D. Howe Institute.

Alex Usher is President, Higher Education Strategy Associates.

This E-Brief is available at www.cdhowe.org.

Permission is granted to reprint this text if the content is not altered and proper attribution is provided.

The views expressed here are those of the author. The C.D. Howe Institute does not take corporate positions on policy matters. 